\title{
Dinero, poder y religión: el problema de la dis- tribución de los diezmos en la diócesis de Buenos Aires (1776-1820)'
}

\author{
Roberto Di Stefano ${ }^{2}$
}

\section{Introducción}

Los recursos provenientes de los diezmos constituían uno de los principales ingresos de las Iglesias coloniales, por lo que la evolución de la masa decimal de un obispado y el sistema que regía su distribución constituyen un tema de ineludible abordaje en el estudio de las rentas diocesanas. En el caso de Buenos Aires, sin embargo, si bien las fuentes relativas al cobro de los diezmos fueron utilizadas para calcular el volumen y definir la composición de la producción agropecuaria, han sido en cambio prácticamente ignoradas en los estudios de historia religiosa ${ }^{3}$.

Sólo en los últimos años se ha comenzado a sentir entre los investigadores la necesidad de encarar seriamente el tema de las rentas eclesiásticas, a partir

1-Una versión preliminar de este trabajo fue presentado a las XVI Jornadas de Historia Económica realizadas en la Universidad Nacional de Quilmes en setiembre de 1998. Agradezco los comentarios y sugerencias de José Carlos Chiaramonte, Jorge Gelman, Judith Farberman, Juan Carlos Garavaglia, Valentina Ayrolo y de los evaluadores de Quinto Sol.

2-Instituto de Historia Argentina y Americana "Dr. Emilio Ravignani" (UBA). Investigador del CONICET.

3-A fines de los años ' 80 tuvo lugar un intenso debate acerca de la fisonomía de la campaña del litoral rioplatense, y los datos provenientes de los diezmos constituyeron, junto a las contabilidades de establecimientos rurales, una de las fuentes privilegiadas por los investigadores involucrados en él, como es el caso de Garavaglia J. C. (1987:13-64), García Belsunce C. (1988: 317-355), Amaral S. y Ghio J. M. (1990). 
de la doble constatación de la importancia de la Iglesia en la economía colonial y el atraso en que se encuentran nuestros conocimientos en relación a los de otros países. Como fruto de esta incipiente renovación historiográfica han empezado a afrontarse temas como los efectos de los decretos de desamortización eclesiástica en el Río de la Plata, el complejo funcionamiento de las capellanías y otras obras pías, la presencia económica de la Iglesia en la campaña rioplatense o la práctica de la limosna ${ }^{4}$. La economía de las órdenes religiosas, por su parte, también ha comenzado a recibir una cierta atención, gracias a algunos trabajos de gran calidad que han tomado como objeto determinados aspectos de la economía conventual o el estudio global de las actividades de una de las órdenes presentes en Buenos Aires ${ }^{5}$.

Pero si se intenta buscar, en las más tradicionales obras de historia de la Iglesia, una respuesta a la cuestión central de cuáles eran los ingresos del clero secular y los de las estructuras eclesiásticas de la diócesis de Buenos Aires, el resultado será más bien descorazonador. La primera de estas cuestiones mereció sólo la breve incursión en el tema de F. Avellá Cháfer y el parcial tratamiento de la cuestión en el marco de dos tesis de doctorado ${ }^{6}$. Menos trabajado aún es el caso de las rentas diocesanas, las cuentas de las parroquias y de otras estructuras eclesiásticas controladas por el clero secular, a pesar de que poseemos numerosas fuentes que pueden ayudarnos a aprender mucho sobre ellas, como los libros de fábrica, los mismos diezmos, o algunos procesos judiciales.

En este trabajo nos hemos propuesto ofrecer una aproximación a la compleja cuestión de las rentas del obispado a partir de los ingresos de los diezmos, que según afirmaba el cabildo eclesiástico en 1776 constituían "el principal fondo" de las rentas del cuerpo catedralicio y sin duda también una de las principales entradas de la diócesis ${ }^{7}$. Como fuente básica de la investigación hemos utilizado los cuadrantes de los diezmos del período 1776-1820, que con algunas lagunas proporcionan una documentación muy rica y bastante homogénea, que abarca desde la fundación de Virreinato del Río de la Plata hasta la abolición del impuesto por la reforma eclesiástica de $1821^{8}$. Trataremos de mostrar

4-Véase respectivamente A. Levaggi (1986:7-98) y (1992); Barral M.E.(1996 y 1998:7-33)

5-Véase Mayo C. y Peire J. (1991:147-157) y Mayo C. (1991)

6-Avellá Cháfer F. (1981:283-310 y 1980:295-318); Di Stefano R. (1998). Existen otros trabajos que se ocupan del tema. Una visión muy general sobre las rentas eclesiásticas, incluidos los diezmos, fue ofrecida por Udaondo E. (1949:16-18, y antes aún por Chacaltana C. (1885). Más recientemente se ha ocupado del tema Auza N. T. (1981:3-28 y en particular págs. 5-7)

7-AGN IX 24-8-3, Representación del cabildo eclesiástico de Buenos Aires a S. M. del 5 de abril de 1776, ff. 86-90.

8-Los cuadrantes se conservan en AGN IX 13-1-9. 
que la distribución de los diezmos constituyó un elemento generador de alta conflictividad en el interior de la Iglesia y en las relaciones de sectores del clero con la Corona durante los últimos decenios coloniales, situación que sin duda jugó además su papel en el proceso de politización revolucionaria que interesó a buena parte del clero secular en el siglo XIX.

\section{El diezmo, de Palestina al Río de la Plata}

El problema de los diezmos remite a una de las cuestiones centrales de la historia del cristianismo: ¿Con qué recursos se sostiene el culto? ¿De qué entradas pueden gozar los sacerdotes? ¿Es lícito que desarrollen actividades económicas para vivir?, ¿No descuidan de tal modo la atención pastoral de su comunidad y el servicio del culto? Esta serie de interrogantes revela su cabal relevancia cuando consideramos que de las posibles respuestas depende el lugar que se le asigne al clero en la vida de la Iglesia y en la sociedad, el rol social del sacerdote, su relación con su comunidad religiosa y hasta las relaciones entre poder civil y poder espiritual en las sociedades de Antiguo Régimen'. En virtud de su relevancia, la cuestión ha atravesado la historia de la Iglesia desde sus albores: del Beati pauperes evangélico al "donde hay mucho dinero hay mucha bendición" del Arcipreste de Hita; de la carta de Santiago a la cuestión de la simonía en tiempos de la reforma gregoriana; del problema del trabajo y la riqueza en las comunidades monásticas a la discusión del tema en las órdenes mendicantes; de los recurrentes episodios y movimientos de protesta, a veces violentos, por el retorno a la Iglesia pobre y espiritual hasta llegar, en pleno siglo XX, al debate sobre los curas obreros, primero en Francia y luego en otros países. La tensión generada entre una fuerte tradición pauperística propia del cristianismo y la tendencia de las instituciones eclesiásticas a acumular riquezas, abandonando lo que desde dicha tradición se ha señalado y se señala como uno de los elementos identitarios fundamentales de las enseñanzas de Jesús, ha signado la historia religiosa del mundo cristiano desde los orígenes. Expresa tal tensión de manera extraordinaria el Dante, dirigiéndose a los culpables de simonía que penan eternamente en el infierno:

"Fatto v'avete dio d'oro e d'argento;

e che altro è da voi all'idolatre,

se non ch'egli uno, e voi ne orate cento?

Ah, Costantin, di quanto mal fu matre, 
non la tua conversion, ma quella dote

che da te prese il primo ricco patre!

(Inferno, 19, 112-117)

¿De qué fuentes podían los cristianos tomar elementos para afrontar una cuestión tan delicada? Las referencias del Evangelio a la cuestión económica podían suscitar reflexiones de honda espiritualidad, pero no resolvían el problema en forma práctica. No se podía hacer funcionar las estructuras eclesiásticas, siempre más complejas y dirigidas a la atención de un mayor número de fieles, con recomendaciones como la de "Mirad los lirios cómo crecen; ni trabajan ni hilan..." (Lucas 12, 27). En la medida en que la Iglesia se expandía por Asia Menor, el norte de Africa y Europa, la situación se agravaba, y de hecho se volvió insostenible en el siglo IV, cuando el cristianismo fue declarado religión oficial del imperio y la Iglesia pasó a ser una institución prácticamente subsumida en sus estructuras del estado romano ${ }^{10}$. Hasta entonces las actividades de las comunidades, los sacerdotes y el culto se habían sostenido por medio de donaciones voluntarias de los fieles; a partir de entonces iría tomando forma el concepto de beneficio eclesiástico".

Fue en efecto hacia el siglo IV que algunos Padres de la Iglesia (San Jerónimo, San Agustín, San Juan Crisóstomo) comenzaron a recomendar a los fieles el retorno a la contribución del diezmo, una obligación para con el culto de la que los primeros cristianos se habían sentido liberados, junto a otras cargas y obligaciones prescriptas por la Ley mosaica. El diezmo era, en efecto, una contribución de origen veterotestamentario: Abram concedió al Sumo Sacerdote Melquisedec, rey de Salem, el diezmo del botín que confiscó a sus enemigos (Génesis 14, 20), y el Levítico $(27,30-32)$ señala que la décima parte

10-Véase, para una visión sintética de las transformaciones ocurridas, Pricoco S. (1997:288-292).

11-La reflexión cristiana de los primeros siglos se basaba en ciertas expresiones de Jesús, tales como “... el obrero es digno de su salario" (Lucas 10,7), y de San Pablo, quien en la primera carta a los cristianos de Corinto había planteado la cuestión muy claramente: "¿... no sabéis que los que ejercen las funciones sagradas comen del santuario, y los que sirven al altar, del altar participan? Pues así ha ordenado el Señor a los que anuncian el Evangelio: que vivan del Evangelio..." (1 Corintios 9, 13-15). Véase sobre este tema M. Guasco, Storia del clero..., cit.. Sobre el concepto y desarrollo histórico del beneficio eclesiástico la bibliografía es interminable. Permítasenos señalar a modo de ejemplo el trabajo de Meuvret J. (1968:4768) que aporta útiles sugerencias metodológicas, así como lo hace Brambilla E. (1984: 395-450) en el marco de un interesante debate que ocupó las páginas de dicha revista en los primeros años ' 80 . También se ocupan de la cuestión de los beneficios, para Francia, Plongeron B. (1974:24-31) y Chatellier L. (1970:75-98). Entre los muchos trabajos que hay para el sur de Italia en la época de la dominación española, podemos destacar el tercer capítulo de Russo C. (1984). Un trabajo clásico en la materia es el de Le Bras G. (1964:572-578). Una visión histórico-canónica en Mollat G. (1937) 
de todas las semillas, frutos de árboles y ganados mayores y menores pertenecen a Yavé. Lo mismo prescribe el Deuteronomio (14, 22-29), y podríamos extendernos con las citaciones bíblicas.

En el mundo cristiano occidental hay testimonios del pago del diezmo a partir del siglo $\mathrm{VI}$, y en las postrimerías de la centuria ya se lo considera obligatorio en algunas zonas' ${ }^{12}$. En otras, como en España, no hay evidencias de tal obligatoriedad hasta el siglo XII, cuando la contribución es mencionada en el canon segundo del Concilio de Palencia de $1129^{13}$. De Europa la institución decimal pasó a América, condicionada por particularidades derivadas del ejercicio del patronato regio, ya que junto con la cesión de los derechos de patronazgo sobre las Iglesias americanas, la Santa Sede concedió a la Corona española el control sobre los diezmos por bula del 16 de diciembre de 1501 . En el siglo XVIII, en virtud del siempre más acentuado regalismo borbónico, los diezmos llegaron a ser considerados como un ramo de la real hacienda ${ }^{14}$.

Los reyes de España "donaron" a las Iglesias americanas los diezmos para financiar el sostenimiento del culto, las actividades pastorales, la construcción de iglesias y el funcionamiento de los hospitales, pero siempre mantuvieron un fuerte control sobre el impuesto: por un lado, como veremos, una parte de lo recaudado pasaba a la real hacienda; por otro, la Corona decidía sobre las modalidades de pago y distribución de los diezmos, decretando por ejemplo ramos de producción afectados y exenciones, como parte de la densa maraña legislativa colonial.

\section{La recaudación y distribución de los diezmos en Iberoamérica colonial}

¿Quién pagaba diezmos en la América española y cómo se los recaudaba y distribuía? La respuesta no es simple, dado que existieron variantes de región a región y también hubo cambios en diferentes períodos. La legislación de base estaba incluida en las Leyes de Indias, bajo el Título XVI -"de los diezmos-, donde se establecían las reglas universales que debían regir "donde lo contrario -decía el rey-no estuviere mandado por Nos, ú ordenado por las erecciones de las Iglesias". El problema era que "lo contrario" a lo dispuesto en la legislación

12-Véase Guasco M. (1997), Cap. I, "Dalle origini al Concilio di Trento".

13-Véase Garzón Pareja M. (1974:22). Sobre el pago de diezmos en España puede consultarse también Barrio Gozalo M. (1982) y Ibáñez Rodríguez S. (1999).

14-Véase Brading D. (1994:26 y 236). El rey, en Real Cédula de 19 de octubre de 1774, había reafirmado "la propiedad y absoluto dominio que tiene en estos Diezmos como bienes Patrimoniales, que son de su Corona..." y "un Ramo de vra. Real Hacienda", tal como afirmaba el cabildo eclesiástico en un memorial de 1776 que se conserva en AGN IX 24-8-3, ff. 86-90. 
general se verificaba en una gran cantidad de casos, de manera que realizar consideraciones generales para el entero universo indiano resulta altamente dificultoso, y el hacerlo suponiendo la vigencia universal de las leyes de Indias, temerario. Había comunidades indígenas, por ejemplo, que estaban eximidas de la contribución, y también los religiosos, en especial la Compañía de Jesús, gozaron por períodos y en ciertas zonas de exenciones, por no hablar de las innumerables disposiciones acerca de cómo distribuir el producto de esta tasa, que a menudo variaban de obispado a obispado.

En el siglo XVIII, como resultado de las crecientes necesidades económicas de la Corona, las exenciones tendieron a ser anuladas y se intentó avanzar hacia una homogeneización de las reglamentaciones. Por lo que hace específicamente al Río de la Plata, ya en 1666 una Real Cédula había decidido que todas las órdenes religiosas se ajustaran al pago $^{15}$, y en 1748 se mandaba que también los treinta pueblos jesuíticos del Paraguay lo hicieran, para pagar los salarios de los curas de las reducciones de Santa $\mathrm{Fe}^{16}$. Dos años más tarde se extendía el pago a todos los colegios de la Compañía ${ }^{17}$, y en 1751 les tocó el turno a los indios Chiquitos de Santa Cruz de la Sierra ${ }^{18}$. El control empezaba a acentuarse: en 1761 se pedían informes acerca del cumplimiento del pago por parte de las órdenes mendicantes ${ }^{19}$, y en 1770 se ordenaba al cabildo eclesiástico de Buenos Aires que controlara el pago por parte de los jesuitas, que según parece habían logrado eludir, por lo menos en parte, las ordenanzas anteriores $^{20}$. La Corona española iba agregando, de este modo, nuevas disposiciones a las ya existentes, con sucesivas Reales Cédulas a veces contradictorias entre sí, o lo suficientemente ambiguas como para permitir muy diferentes interpretaciones, que daban lugar a su vez a prolongados reclamos y procesos.

Por otra parte, la recaudación de los diezmos se veía afectada por factores naturales y sociales. Por un lado, su cobro presentaba serias dificultades, por lo que muchas veces las autoridades eclesiásticas cedían el derecho de recogerlo a particulares que, a cambio de una suma fija, se convertían en "diezmeros". Conocedores expertos de las dinámicas de la producción agrícola y bien informados de las perspectivas de cada cosecha, los diezmeros ofrecían en pública almoneda una suma a cambio del derecho de recaudar la totalidad o una parte del diezmo de alguna jurisdicción en particular o de varias de ellas. Las difi-

15-AGN, Reales Cédulas, Tomo 5, f. 301, Real Cédula del 24 de marzo de 1666.

16-AGN, Reales Cédulas, Tomo 46, № 36 bis, Real Cédula del 26 de agosto de 1748.

17-AGN, Reales Cédulas, Tomo 16, f. 265, Real Cédula del 9 de enero de 1750.

18-AGN, Reales Cédulas, Tomo 38, f. 204, Real Cédula del 19 de enero de 1751.

19-AGN, Reales Cédulas, Tomo 18, f. 137, Real Cédula del 8 de diciembre de 1761.

20-AGN, Reales Cédulas, Tomo 20, f. 163, Real Cédula del 17 de enero de 1770. 
cultades en el cobro tenían como consecuencia que en ocasiones la operación durase meses y hasta años, por lo que era común que las cuentas de un determinado cuadrante o ejercicio no pudieran cerrarse sino en fechas bastante posteriores.

Pero además los diezmos reflejaban la evolución de los precios de los productos afectados al pago, por lo que una muy exigua cosecha de trigo podía resultar tan negativa para las arcas eclesiásticas como otra excelente: en ambos casos la recaudación se veía resentida, en un caso por la escasez y en el otro por la excesiva abundancia, que hacía caer los precios. Podemos apreciar este fenómeno en la siguiente cita, extraída de una representación del cabildo eclesiástico de Buenos Aires de 1776:

"En el año de 74 en que fue copiosissima la cosecha del Trigo con acuerdo de vuestros Oficiales Reales se quedó la Iglessia coneste Diezmo que haze el principal fondo de nras rentas por no haber habido quien lo rematasse, y adjudicado en especie à cada interesado, apenas pudimos sacar con el precio desu venta lo suficienre para satisfacer los costos desu recojida y almacenaje (...). En este año de 76 se há quedado tambien la Iglessia coneste Diezmo à causa de haber sido tan escasa la cosecha, que no hubo quien ofreciese cosa alguna, teniendo todos presentes, que con el mucho Trigo que restaba deel año antecedente continuaria la misma extrema decadencia, de su precio como efectivamente seha verificado..." ${ }^{\prime 21}$

Por lo que hace a la distribución, la legislación española establecía en principio que la masa decimal -después de haberse deducido un 3\% destinado al seminario conciliar, impuesto del que solamente estaba exenta la Coronadebía dividirse en cuatro partes, la primera de las cuales se asignaba al obispo y la segunda al cabildo eclesiástico. El restante $50 \%$ se dividía a su vez en nueve fracciones, que se distribuían entre la Real Hacienda -dos novenos, llamados comúnmente "reales" o "de Su Majestad"-, los párrocos y otros ministros del culto -los cuatro novenos beneficiales-, los hospitales y la fábrica de las iglesias, que recibían un noveno y medio respectivamente ${ }^{22}$.

En el caso del Río de la Plata, después de la revolución de 1810 el problema que se suscitó con el control de los diezmos fue si el derecho de cobrarlos, como parte del patronato otorgado por la Santa Sede a la Corona, residía en ésta o en la persona de cada monarca. Dos teólogos del Río de la Plata, al ser

21-AGN IX 24-8-3, Reales Cédulas, T. 23, Representación del cabildo de Buenos Aires del 5 de abril de 1776, ff. 86-90.

22-Véase el ensayo de Ronal Escobedo Mansilla en AAVV (1992, en particular pág. 101) 
consultados por la Junta revolucionaria, se inclinaron por la segunda posibilidad y opinaron, en consecuencia, que el nuevo gobierno sucedía a la Corona en el derecho a ejercer el régimen de patronato, por lo que era en última instancia el depositario de los diezmos.

\section{La manzana de la discordia}

El reparto de los diezmos en Buenos Aires constituyó una fuente permanente de conflictos en el interior de la Iglesia y entre las autoridades eclesiásticas y civiles $^{23}$. En nuestra opinión, las tensiones provenientes de este ámbito, sumadas a otras de carácter ideológico y disciplinario, crearon situaciones de intenso malestar y disconformidad que se hallaban irresueltas en vísperas del estallido revolucionario y que tuvieron un papel en la politización del alto clero secular. Contrariamente a cuanto suele suponerse, los cuerpos que componían la sociedad colonial -y en general las de Antiguo Régimen- no eran entidades compactas en las que reinaba unánime consenso, sino que estaban atravesados por antagonismos que deben convertirse en objeto de estudio ${ }^{24}$.

Pero además, en el caso de la Iglesia, confrontaciones que tenían por origen diferencias en la distribución de las rentas se entrecruzaban inextricablemente, a menudo, con otras menos pedestres. Es que, por un lado, la renta que percibía cada interesado señalaba al mismo tiempo el lugar relativo que ocupaba dentro de la estructura eclesiástica y en el orden social; por otro, el tema de la distribución estaba relacionado con distintas concepciones teológicas acerca de la naturaleza de la Iglesia. Por ejemplo: que el cabildo eclesiástico, órgano de representación y gobierno del clero secular, percibiera en su conjunto menos dinero que el obispo, o viceversa, respondía no sólo a consideraciones de tipo económico, sino además a diferentes modelos de fun-

23-Los ejemplos de Reales Cédulas y Reales Ordenes dedicadas a este tema son muy numerosos. Véanse por ejemplo las de 11 de junio de 1755 y 23 de junio de 1757 en AGN IX 24-7-11, ff. 240 y 366 respectivamente; las de 10 de abril de 1761 y 14 de julio de 1765 en AGN IX 24-7-12, ff. 111 y 311; las de 6 de marzo, 16 de mayo, 24 de agosto de 1770 en AGN IX 24-7-14, ff. 180, 256 y 289; y especialmente las que se ocupan más concretamente de la distribución de la masa decimal, a saber: la de 7 de noviembre de 1772 en AGN IX 24-8-1, f. 248; 9 de junio de 1775 en AGN IX 31-8-7, Justicia Leg. 49, expte. 1348, f. 39; 29 de junio del mismo año en AGN IX 24-8-2, f. 38; 19 de mayo de 1777 en AGN IX 24-8-3, f. 85 y 25 de noviembre de 1782 en AGN IX 24-8-4, f. 361.

24-La cuestión teórico-metodológica ha sido bien planteada por Guerra F.-X. (1989). Para las cuestiones de etiquetas y precedencias puede verse con provecho también Elias N. (1982) en particular el Cap. V, "Etiqueta y ceremonial", en el que el autor analiza la cuestión para el caso de la fastuosa corte de Luis XIV. Para el Río de la Plata véase Garavaglia J. C. (1996). Para el caso concreto de la Iglesia porteña, F. Urquiza (1993) ha realizado una importante contribución al estudiar los conflictos de etiquetas de fines de la segunda mitad del siglo XVIII. Véase también Di Stefano R. (1999). 
cionamiento eclesial. En uno de ellos el obispo ocupa un lugar preminente, por encima de su clero, que aparece subordinado al prelado; en el otro el clero, representado por el cabildo, se coloca en pie de igualdad con el obispo en un esquema en el que predomina la horizontalidad de las relaciones. Esta última postura fue propiciada, por ejemplo, por sectores del clero influenciados por ideas galicanas, jansenistas e incluso richeristas, corrientes de pensamiento que recurrían al modelo de la Iglesia primitiva en su lucha por la reforma eclesiástica, por una distinta ingeniería institucional que devolviera a las Iglesias una mayor autonomía respecto de Roma, y restituyera al clero, y en algunos casos también a los laicos, un mayor protagonismo dentro de la vida eclesial. Algunos pensadores jansenistas o cercanos a esta corriente proponían, de hecho, la elección de los obispos por la misma Iglesia local, con participación del clero y a veces de los laicos, según el esquema de la Iglesia de Utrecht ${ }^{25}$.

Lo que nos interesa subrayar es que ecos de estas controversias eclesiológicas se dejaron sentir en el Río de la Plata y que ello incidió en las confrontaciones por la distribución de las rentas y en las relaciones internas del clero, por lo que las discusiones por la distribución de los diezmos o de otras rentas eclesiásticas no representaban meramente disputas de índole económica, sino que poseían una profundidad mucho mayor, connotaciones mucho más trascendentes. El tema es, como se ve, rico y complejo, aunque no es éste el lugar para

25-El cabildo eclesiástico de esta Iglesia de Holanda, al ser destituido por Roma el vicario Pedro Codde, acusado de jansenismo, decidió elegir un arzobispo por su propia cuenta y designó como tal en 1723 a Cornelius Steenoven. La fundamentación teológica de tal decisión se basa en la consideración, por parte del cabildo, de que era lícito a la Iglesia de Utrecht reasumir el derecho a elegir a sus propios prelados, que en algún momento había delegado en la Santa Sede. A partir de este hecho se generó un amplio movimiento, de alcance europeo, de solidaridad con la Iglesia de Utrecht, movimiento en el que se comprometieron los núcleos jansenistas más activos. Sólo en 1853 se restableció la jerarquía romana en la diócesis holandesa. Los richeristas fueron los seguidores del teólogo francés Edmund Richer (1559-1631), quien sostenía que el oficio de los párrocos es de institución divina, es decir, que el poder de jurisdicción por delegación de los obispos. Llegó incluso a afirmar que la autoridad reside en la totalidad de la Iglesia en tanto que comunidad de fieles. La tesis sobre la institución divina de los párrocos tuvo fuerza en los siglos XVII y XVIII -cuando Pietro Tamburini, en la Universidad de Pavía, la enunciaba abiertamente ("Pastores secundi ordinis, seu presbiteros, jurisdiccionem habere jure divino contendimus") y sobrevivió hasta aún más tarde, al punto de que en la segunda mitad del XIX se veía todavía la necesidad de desautorizarla. Cfr. la voz "Parroquia" del Diccionario Teolójico, Canónico, Jurídico, Litúrjico, Bíblico, etc. por el Ill.mo. i Rmo. Sr: D. Justo Donoso..., Valparaíso, 1855-1859. Richer fue autor del De Ecclesiastica et politica potestate (París, 1611) y de las Vindiciae doctrinae majorum de auctoritate Ecclesiae in rebus fidei et morum (Colonia, 1683). Otro pensador del siglo XVII que defendió ideas en la misma línea fue Pierre de Marca, arzobispo de Toulouse y más tarde de París, en su De concordia sacerdotii et imperii (1641). Véase sobre este tema Vilanova E. (1989:792-794) y Alberigo G. (1964). Sobre la eclesiología jansenista véase Plongeron B. (1967) y para el ciclo revolucionario francés en general, el tercer capítulo de Plongeron B. (1969). 
desarrollarlo de manera más exhaustiva. Digamos sólo a modo de ejemplo que en un conflicto que se desató en 1783 entre el obispo Malvar y Pinto y el cabildo eclesiástico, por cuestiones que tenían que ver también con la distribución de los diezmos entre ambas partes, el representante del cuerpo capitular escribía al prelado que

"... para establecer alguna cosa en su Diócesis, para corregir lo que es digno de corrección, y para desarraigar los abusos que se hubieran introducido debe proceder según el consejo del Cabildo que es el Senado de su Iglesia..." ${ }^{26}$

Aclarado este punto conviene preguntarse qué significaban los diezmos en términos estrictamente económicos para la Iglesia y qué evolución siguieron las sumas recaudadas a lo largo del período en estudio ${ }^{27}$. El gráfico que sigue puede ayudarnos a responder a esta pregunta. Ver Anexo gráfico 1

Puede notarse que la masa decimal, partiendo de un nivel bastante bajo en 1776, aumenta hasta superar los 100.000 pesos en el primer quinquenio del siglo XIX y luego vuelve a caer hasta ubicarse en torno a los 50.000 pesos en vísperas de su abolición en 1821 por parte del Estado de Buenos Aires. Curiosamente, la misma evolución siguen las ordenaciones sacerdotales de clérigos y las adjudicaciones de capellanías, una "coincidencia" que sería necesario explicar más acabadamente ${ }^{28}$. Las excelentes cosechas que precedieron a la revolución y la consecuente caída de los precios, sumadas a un sistema de distribución que perjudicaba a los capitulares, había obligado a éstos -según decían desconsolados- a vender sus muebles para sobrevivir ${ }^{29}$. Más tarde las turbulencias revolucionarias incidieron decisivamente sobre el cobro del impuesto, y a fines del período estudiado, cuando los diezmos fueron abolidos, no representaban más que un ingreso muy exiguo, sobre todo teniendo en cuenta que en el cabildo eclesiástico se había aumentado el número de dignidades y canónigos.

Por otra parte, las épocas de vacas gordas tampoco estuvieron exentas de

26-AGN, Manuscritos de la Biblioteca Nacional, Leg. 364, ms. 6.378, "El Cavildo Ecco. al S.or Malvar sobre Antifonas y Responsorios". Cfr. sobre este conflicto Di Stefano R. (1999)

27-Una comparación entre la masa decimal de varias diócesis, entre ellas Tucumán y Buenos Aires, en Castañeda P. (1978-1979:95). También trae datos al respecto F. de Azara, Viajes por la América del Sur de don Félix de Azara, comandante de la comisión de límites española en la sección del Paraguay..., Montevideo, (1850: 274) donde compara los diezmos de Buenos Aires y los de Asunción. Azara permaneció en el Río de la Plata entre 1789 y 1801.

28-Véase Di Stefano R. (1998 b)

29-AGN IX 31-9-3, expediente 1551, "El Cavildo Ecleciastico sobre la necesidad de recursos por la escases de rentas" (1809-1810). 
problemas. Más aún: nuestra hipótesis es, en este punto, que los conflictos por los diezmos, al constituir uno de los elementos de enfrentamiento entre múltiples actores -el obispo, el cabildo eclesiástico, el clero de las otras jurisdicciones de la diócesis, los curas y los beneficiados de la catedral, el fisco-, contribuyeron eficazmente a involucrar a la Iglesia en las alternativas del proceso revolucionario. Presentaremos seguidamente aquellos puntos conflictivos relacionados con los diezmos que en nuestra opinión incidieron mayormente en la vida interna del clero secular y contribuyeron a crear el clima de alta conflictividad que presentaba la Iglesia rioplatense al estallar la revolución ${ }^{30}$.

\section{a. La distribución por cuartas partes}

Se trata de una cuestión ya descripta por otros investigadores, por lo que limitaremos la presentación de los hechos al mínimo indispensable e intentaremos poner en discusión algunos supuestos de estos autores para ofrecer seguidamente nuestra interpretación ${ }^{31}$. En 1622, cuando se erigió la diócesis, su primer obispo mons. fray Pedro Carranza decidió que los diezmos se dividirían en tres partes: la primera para la mesa episcopal, la segunda para la capitular y la tercera para los novenos ${ }^{32}$. El hecho de que la división se hiciera por tercios y no por cuartos, como en las demás Iglesias, se fundaba en consideraciones relativas a la pobreza de la región y, como veremos, perjudicaba nada menos que a la Corona.

En el siglo XVIII, en el marco de la creciente afirmación de los derechos reales que caracterizó a la gestión de la casa borbónica, la Corona empezó a presionar a la Iglesia porteña para que la división se empezara a realizar por cuartas partes, con lo que los dos novenos "de Su Majestad" se extraerían de la mitad de la gruesa y no de un tercio. Esta reforma propuesta por la metrópoli se superponía por otra parte a las gestiones tendientes a aumentar las prebendas del cabildo, con la consecuente disminución de las rentas de las ya existentes. Estas cuestiones, si bien cuentan con antecedentes en el decenio anterior, podemos decir que se trataron intensamente entre 1765 y $1775^{33}$.

Hasta aquí los hechos. Por lo que hace a las interpretaciones, a nuestro juicio tanto Bruno como Avellá Cháfer abordaron la cuestión desde una perspectiva parcial, presentándola como un episodio en el que se ven enfrentadas

30-R. Di Stefano R. (1998)

31-Bruno C. (1969:352-354) y Avellá Cháfer F. (1980, primera parte)

32-El decreto de erección puede consultarse en F. Actis, Actas y documentos del Cabildo Eclesiástico de Buenos Aires, Buenos Aires, 1944, Libro I. El asunto de los diezmos figura especialmente en las págs. 11 y 19. Hay copia del decreto de erección en AGN IX 31-8-7, Justicia Leg. 49, expte. 1398, ff. 46-56.

33-Véase sobre este punto Probst J. (1941). 
las autoridades eclesiásticas y las civiles, cuando en realidad se trata de un litigio más complejo, que divide posiciones en el interior del estrato del clero que percibía partes -desiguales- de los diezmos ${ }^{34}$. En efecto, como decíamos la división tripartita comportaba elecciones que claramente favorecían a ciertos clérigos y perjudicaban a otros: mientras el obispo y el cabildo eclesiástico recibían respectivamente un $33 \%$ de la masa decimal en lugar del $25 \%$, los destinatarios de los novenos -la Real Hacienda, los párrocos de las iglesias matrices y sus demás ministros- veían recortados sus ingresos. La creación de nuevas prebendas tenía también implicancias contrapuestas para distintos protagonistas: es cierto que redundaba en perjuicio de los capitulares que detentaban las sillas existentes -porque la renta de la mesa capitular debía repartirse entre más prebendas-, pero también lo es que beneficiaba en general al clero secular de la diócesis, que a partir de entonces habría de contar con nuevos beneficios eclesiásticos en el cabildo ${ }^{35}$.

La distribución por cuartas partes se ejecutó a partir de 1776. El reclamo del rey buscaba que la masa decimal comenzara a dividirse en cuatro porciones, visto que la "cortedad de las rentas" -que se había alegado tan repetidamente para asignar a los novenos sólo un tercio del total- había sido superada gracias al aumento de la producción agropecuaria. Los perjudicados con la nueva política fueron el obispo y el cabildo eclesiástico, que ya no recibieron entre ambos los dos tercios del total sino sólo la mitad, mientras los sectores del clero que percibían los cuatro novenos beneficiales (párrocos y beneficiados de las matrices) vieron crecer su participación proporcional en un 48,6\%. Para dar un ejemplo concreto, si en 1794 el sistema de tercios habría asignado a cada noveno beneficial $\$ 1.702$, con la división en cuartos la misma renta ascendía a $\$ 2.530$, con las consecuentes disminuciones para el obispo y los canónigos. Desde esta óptica pueden releerse ciertos conflictos eclesiásticos de la época, como por ejemplo las ruidosas disputas entre mons. De la Torre y el cabildo eclesiástico por un lado y los curas de la catedral por el otro en los años en que se debatía la cuestión ${ }^{36}$.

34 Bruno C. (1969) presenta como protagonistas del conflicto al obispo y el cabildo eclesiástico por un lado y lo que el autor llama "el sector gubernamental" por el otro, sin hacer mención de los otros clérigos interesados en que el asunto se resolviese a favor de la postura de la corona. Avellá Cháfer, (1980) afirma que el litigio "se solucionó en favor de las autoridades civiles".

35-Es lo que ocurrió con la fundación en 1765 de la chantría y la maestrescolía, resultado más inmediato de este litigio: el magistral F. A. Goycoechea pasó a chantre, el canónigo J. de Andújar, a maestrescuela, y al quedar liberadas sus sillas permitieron el acceso al cabildo de J. J. Fernández de Córdoba y más tarde de J. B. Maziel.

36-Bruno C (1969:355) 
Podría parecer entonces que la Corona benefició en general a los destinatarios de los novenos. Sin embargo, como veremos en el próximo apartado con mayor detalle, al mismo tiempo que se decidía la división cuatripartita, una Real Cédula ordenaba que a los curas y ministros de la catedral se les pagara de los diezmos un salario fijo, y que el resto de los cuatro novenos beneficiales se asignara al cabildo en calidad de superavit, como forma de compensar las pérdidas de la mesa capitular. De esta forma, las rentas del cabildo se vieron reequilibradas, mientras el obispo y los sacerdotes beneficiarios de los cuatro novenos salieron perjudicados.

\section{b. El reparto de los cuatro novenos beneficiales}

La distribución de los cuatro novenos beneficiales fue modificada por Real Cédula de 1775. Hubo luego dos reglamentos, que se redactaron en 1782 y 1795, y una decisiva modificación de las prácticas vigentes a partir de 1805. Como hemos señalado, los cuatro novenos de la mitad de la gruesa, luego de algunos descuentos ( $3 \%$ para el seminario, sumas variables para gastos generales y otros ítems) debían repartirse entre la fábrica de la iglesia matriz (un noveno y medio), el hospital (otro noveno y medio), la Real Hacienda (los dos novenos "de Su Majestad") y un grupo de sacerdotes entre los que figuraban los párrocos de la matriz (el de españoles y el de naturales) y los titulares de otros beneficios afectados al servicio del culto.

La Real Cédula de 1775, como decíamos, ordenó que se adjudicara a los curas y ministros de las matrices un salario fijo deducido de los cuatro novenos y que el resto se asignara a la mesa capitular en carácter de superavit. Este régimen empezó a regir a partir del reglamento de 1782 y se aplicó retroactivamente desde 1776, generando beneplácito en los miembros del cabildo eclesiástico e irritación entre los beneficiarios de los cuatro novenos, que salieron rotundamente perjudicados ${ }^{37}$. El conflicto puede visualizarse muy claramente en un proceso iniciado por el sacristán mayor de la catedral, pbro. Juan Manuel

37-El reglamento de 1782 en AGN, Manuscritos de la Biblioteca Nacional, m. 5036, "Providencia de la Junta de Diezmos de Buenos Aires regulando los 4/9 que debe percibir el cabildo eclesiástico" [mayo de 1782]. Es interesante que también en 1782 haya estallado un sordo conflicto entre el obispo y el cabildo por cuestiones litúrgicas en el que los capitulares señalan, como otro motivo de la animadversión del prelado hacia ellos, la distribución de los cuatro novenos según el reglamento establecido ese mismo año. El cabildo afirma que el obispo "... se habia propuesto darle à su arbitrio un destino mui diferente, deel que el Soberano le aplicaba, y quitarle al Cabildo el derecho que le quedaba al Sobrante segun Leyes, y Cedulas Reales, se hà resentido... "Este tipo de cruces pone en evidencia la necesidad de estudiar en toda su complejidad los poliédricos conflictos que atravesaban la Iglesia colonial. Cfr. sobre esta cuestión Di Stefano R. (1999) 
Ximenez, en 1804. Ximenez, que se sentía estafado por la modificación del sistema, encontró un modo muy inteligente y eficaz de hacer oir su voz y capitalizar la adversidad: perdido por perdido, decide donar las rentas no percibidas al rey, a la sazón abrumado por la catástrofe en que España se estaba precipitando en aquellos primeros años del siglo $X I X^{38}$.

Pero la política regia favorable a los capitulares duró un decenio, hasta 1786, cuando una nueva Real Cédula dirigida a todas las Iglesias americanas dispuso que los cuatro novenos fuesen distribuidos entre los sacerdotes de las parroquias y que ya no se asignara el superavit a los cabildos. Una disposición, ésta, que naturalmente generó grandes resistencias, desde Nueva España hasta el Río de la Plata ${ }^{39}$. Los cabildos eclesiásticos, gracias al gran poder con que contaban en América, pudieron conservar el status quo por unos años, hasta 1788. Así sucedió en Nueva España y también en Buenos Aires, donde sin embargo la Corona volvió al ataque quince años más tarde, en 1803, con una nueva Real Cédula que mandaba ejecutar la anterior ${ }^{40}$.

Se mandaba ahora que los cuatro novenos fueran distribuidos entre todos los párrocos de la diócesis y no solamente entre los de las matrices, corrigiéndose así una práctica "...errónea, voluntaria, parcial, y dirigida à aumentar la renta de la Mesa capitular". De este documento se tomó razón en Buenos Aires en mayo de 1804 y su contenido comenzó a aplicarse a partir de 1805, pero a medias: se quitó el superávit de los cuatro novenos al cabildo, pero no se distribuyó entre los párrocos de todo el obispado sino que se depositó en la clavería e ignoramos -pero imaginamos- cuál fue su destino final.

Vemos entonces cómo la Corona podía, apoyándose en un sector u otro del clero, modificar las condiciones vigentes en favor de determinados objetivos dictados por sus convicciones religiosas y las necesidades de su política social -como lo fue el intento de extender el beneficio de los diezmos a los sacerdotes dedicados a la pastoral, vistos en esta época como emisarios de "civilización" en las campañas signadas por la barbarie y la irreligión $\mathrm{n}^{41}$ - o para intentar cubrir una parte de sus déficits financieros. La documentación demuestra que estos reordenamientos provocaban sordas tensiones entre los eclesiásticos, que veían aumentadas o disminuidas sus rentas con la llegada de una Real Cédula.

38- AGN IX 31-8-7, Justicia, Leg. 49, expte. 1398, "Sobre la oferta o donatibo qe de sus sueldos no cobrados ha hecho a S M el Sacristan de esta Iglesia Cathedral Dn Juan Manuel Ximenez [1805]".

39-La Real Cédula, con el n. 5328, data del 23 de agosto de 1786 y se conserva en AGN IX 24-8-5, Reales Cédulas, Tomo 25, ff. 233 y ss. Brading, op. cit. pág. 237, hace referencia a su recepción en Nueva España. 40-Véase D. Brading, op. cit., pág. 239 y Real Cédula del 3 de octubre de 1803 en AGN IX 24-8-10, Reales Cédulas, Tomo 30, ff. 146 y ss.

41-Sobre la reformulación del rol del clero parroquial en la política borbónica cfr. Di Stefano R. (2000) 


\section{c. La distribución regional de los diezmos}

En el período 1776-1820 la diócesis de Buenos Aires estaba dividida en cuatro jurisdicciones cuyas iglesias matrices funcionaban como cabeceras de diezmos: Buenos Aires, Montevideo, Corrientes y Santa Fe. La conflictualidad tiene origen en este caso en el hecho de que las tres últimas debían enviar a la capital la mayor parte de sus diezmos para completar las rentas del obispo, del cabildo eclesiástico, de los ministros de la catedral y la porción correspondiente a la Real Hacienda. Trataremos de cuantificar esta especie de "subsidio" que el resto de la diócesis debía conceder a la cabecera del obispado ${ }^{42}$.

En principio, las tres jurisdicciones contribuían con el 3\% de la gruesa para el funcionamiento del seminario, una institución educativa que funcionó irregularmente en la ciudad de Buenos Aires y que estaba controlada por el obispo y por el cabildo eclesiástico; es decir, en la práctica, una realidad muy lejana desde la perspectiva del resto de la diócesis ${ }^{43}$. En segundo término, el $50 \%$ de la recaudación iba directamente a las mesas episcopal y capitular, por el sistema de distribución que ya hemos explicado. Los dos novenos de la Corona también iban a la capital y en gran medida allí quedaban, porque en Buenos Aires tenían sede las principales instancias político-administrativas, judiciales y militares. Pero, además, a este importante flujo de recursos se sumaba el llamado "resto líquido" o "superavit" de los cuatro novenos beneficiales, al que hemos hecho referencia en el parágrafo anterior. Se trataba de una cifra variable de los cuatro novenos de las matrices que se agregó, en distintos períodos, a las rentas de los sacerdotes que se desempeñaban en la catedral o a las del cabildo eclesiástico. El ya citado reglamento de mayo de 1782 de la Junta Superior de Diezmos -residente en Buenos Aires- estableció que a los ministros de la catedral, por su cantidad, se les asignaría un noveno y medio de la gruesa y lo mismo a Santa Fe, pero a Corrientes le correspondería sólo un noveno y a Montevideo un noveno y cuarto,

"Desuerte que resultando de dha regulacion dos novenos i medio libres en esta catedral y en la Matriz de Santafe, tres en la de Corrientes, y dos con tres quartas partes en la de Montevideo, se agregara su importe por via de superavit como lo dispone la Real Cedula, a la Mesa Capitular p.a q.e hasiendo un cuerpo con la quarta parte de

42-Corresponde señalar la intuición sobre este punto de Tonda A (1957: 68)

43-Sobre el pago del 3\% para el seminario véase Aznar Gil Federico R., "El clero diocesano", en AAVV (1992:198). 
toda la gruesa que le esta destinada se divida entre las dignidades, Prebendas, y Canongias..."

Entre 1776 y 1820 , en 38 años para los que poseemos datos, este resto ascendió a 4.463 pesos fuertes anuales en promedio, y llegó a representar 17.262 pesos en 1805, una pequeña fortuna. El hecho de que desde 1789 este "resto" incluyera también parte de los cuatro novenos de Buenos Aires no quita significación a esta financiación que la catedral y su clero recibían de las matrices de las demás jurisdicciones.

Pero hay más: un ulterior "subsidio" provenía de lo que se llamaban "casas excusadas" de la diócesis. En España se trataba de los diezmos de la casa mayor diezmera de cada parroquia, que desde tiempos de Felipe II se pagaban a la Corona $^{45}$. En Buenos Aires se aplicaban los diezmos de una o más parroquias de cada jurisdicción a la fábrica de la iglesia matriz o cabecera. En el período que nos ocupa sólo la jurisdicción de Corrientes tenía casas excusadas, y lo eran la parroquia de la misma ciudad y la de San José de las Saladas. Las otras jurisdicciones pagaban en concepto de diezmos excusados, por costumbre, una suma fija: 60 pesos Montevideo, la misma cifra Santa Fe y 200 pesos Buenos Aires. Lo que interesa es que, si hasta 1787 los diezmos excusados se aplicaban a la iglesia matriz de origen, a partir de esa fecha empiezan a incorporarse a las entradas de la fábrica de la catedral, aumentando de este modo el flujo de recursos de las demás jurisdicciones en favor de Buenos Aires. Esta práctica fue anulada definitivamente sólo con la reforma de los diezmos de 1813, casi al final del período, cuando la estructura de la diócesis estaba ya en proceso de disolución por la secesión de las provincias del litoral y la consecuente suspensión del pago de diezmos a Buenos Aires.

El caso de la Banda Oriental es seguramente el más claro para ilustrar la alta conflictualidad de la distribución espacial de los diezmos: el territorio al norte del Río de la Plata estaba dividido desde el punto de vista administrativo entre las jurisdicciones de Montevideo y Buenos Aires. Por este motivo, los diezmos de Colonia, Víboras, Espinillo, Santo Domingo Soriano, Santa Teresa, Rocha, San Carlos y Maldonado no se arrendaban en Montevideo sino en Buenos Aires, lo que agregaba un factor más de irritación. Expresión de la disconformidad respecto a este orden de cosas es la solicitud que en 1811 elevó la Junta de Gobierno de Montevideo para la fundación de un nuevo obispado en la Banda Oriental. En los informes que se remitieron a la Península para funda- 
mentar el pedido, se decía entre otras cosas que "los diezmos de esta banda son ya suficientes para que esta ultima ciudad [Montevideo, RD] tenga su Silla con el Coro correspondiente". De la frase es importante destacar que se habla de los diezmos "de esta banda" y no sólo de los de Montevideo, por lo que la propuesta era sustraer a Buenos Aires la jurisdicción sobre los pueblos arriba mencionados -"que en la división que se propone deben corresponder al Obispado de esta Banda", específica el documento- y establecer la frontera entre las dos diócesis sobre el Río de la Plata y el Uruguay ${ }^{46}$.

En síntesis, Montevideo, Corrientes y Santa Fe conservaban una mínima parte de sus diezmos en relación a lo que debían enviar a la capital: no más que una parte de los cuatro novenos beneficiales, que libres del "resto líquido" y de los "excusados" debían representar entre un 35\% y un $40 \%$ del total. Si a esto agregamos que todos los párrocos, incluidos los orientales, santafecinos y correntinos, debían pagar al obispo, en principio, la cuarta parte de sus ingresos por primicias y derechos de estola, podemos concluir que la situación era decididamente irritante.

\section{d. Los diezmos cobrados por el Estado}

Como ya hemos explicado, el Estado -la Real Hacienda hasta 1810 y su sucesor revolucionario luego- percibía una parte nada desdeñable de los diezmos. Alberto De la Hera afirma, en uno de sus trabajos más recientes, que en el período colonial la parte que la Corona se reservó bajo distintos items -dos novenos, vacantes, etc.- no llegó nunca a cubrir las erogaciones en sentido contrario, es decir, las que desde el Estado colonial se volcaban sobre las Iglesias de Indias ${ }^{47}$. No pretendemos discutir este punto, porque escapa a nuestro propósito. Nos limitaremos a explicar, para la diócesis de Buenos Aires, qué ítems eran asignados a las arcas públicas y qué porcentajes de la gruesa le correspondieron en el período estudiado.

En principio, como llevamos dicho, la Corona percibía dos novenos de la mitad de la gruesa, los dos novenos llamados "de su Majestad"48, que naturalmente mutaban de año a año en proporción exacta respecto de la evolución de

46-Los documentos sobre la creación del obispado en la Banda Oriental están incluidos en el volumen Documentos relativos a los Antecedentes de la Independencia de la República Argentina. Asuntos eclesiásticos, Buenos Aires, Facultad de Filosofía y Letras, 1912, págs. 215-230.

47-De la Hera A. (1992) Caps. XI y XII.

48-Las Leyes de Indias, en su Libro I, Título XVI, Ley xxiij, afirman: "de las otras dos [cuartas del diezmo, RD] se hagan nueve partes, las dos novenas de ellas sean para Nos". Véase la Recopilación de Leyes de los Reynos de las Indias, Tomo I, Madrid, Consejo de la Hispanidad, 1943, pág. 149-150. 
la gruesa. Pero además las arcas reales se reservaban los diezmos que quedaban libres por vacante de los titulares de todas las prebendas. Había dos ítems específicos, el de vacantes mayores, referido a la renta episcopal, y el de vacantes menores, que interesaba a todas las demás prebendas, desde las sillas del cabildo eclesiástico hasta los beneficios simples de las iglesias matrices. Esto quiere decir, en términos más llanos, que cuando vacaba una prebenda la Corona se embolsaba la renta correspondiente. Bajo este título las arcas públicas absorbieron, en 38 años para los que poseemos datos entre 1776 y 1820, 270.979 pesos, es decir, casi un $13 \%$ del total de los diezmos. Por último, el Estado impuso en determinados momentos críticos contribuciones forzosas sobre la masa decimal: entre 1791 y 1793 se debió abonar el denominado "subsidio eclesiástico", que en Buenos Aires sumó 7.011 pesos en total, y entre 1808 y 1812 se debió pagar el "noveno íntegro", que ascendió en total a casi 30.000 pesos. En el gráfico que sigue podemos apreciar el porcentaje de los diezmos que las arcas públicas se reservaron entre 1776 y 1820 . Ver Anexo gráfico 2 .

Como puede observarse, la curva presenta periódicas alzas que se verifican hacia 1777, 1804, 1797 y 1801 . Se trata de la incidencia de las vacantes episcopales, es decir, los años en que por muerte o transferencia del obispo la Real Hacienda cobró íntegramente la renta destinada al prelado, un $25 \%$ de la gruesa. Es posible, pero no podemos afirmarlo con certeza, que la Corona haya especulado tratando de dar largas a los nombramientos eclesiásticos para hacerse del dinero de las vacantes, dado que la duración media de éstas tiende a aumentar a fines del período colonial.

Pero a partir de 1809 la curva ya no baja la línea del 30\%, que hasta entonces había sido sólo sobrepasada en los años de vacancia de la silla episcopal. Aquí, a la incidencia del "noveno íntegro", se suma la sede episcopal vacante que se inició en 1812 por muerte de mons. Benito Lué y Riega. El punto más alto de participación de las arcas públicas en la masa decimal se da en 1813, cuando se llega casi al 50\% del total: un alivio para las finanzas del Estado, obsesionado en obtener recursos para ese barril sin fondo que representaban los crecientes gastos militares. La presión del Estado para financiar las operaciones bélicas se ejerció sobre el conjunto de la sociedad, pero con particular "atención" hacia quienes contaban con dinero constante y sonante: el cabildo eclesiástico, que fue compelido a contribuir además con préstamos forzosos, y los comerciantes, primero los peninsulares y luego también los crioIlos. Si agregamos que el aumento de la porción que fue a parar a manos del Estado coincide con una abrupta caída de la gruesa, que ya no recuperará el récord de 109.212 pesos alcanzado en 1805 , podemos imaginar que la coyun- 
tura era poco favorable para las rentas eclesiásticas. Pero además, como veremos enseguida, no todos los beneficiarios del diezmo resultaron perjudicados por igual.

\section{e. La reforma de 1813, o el desquite del cabildo eclesiástico}

Podemos imaginar el malhumor que la disminución de la gruesa provocaba entre los capitulares porteños: basta recordar que a partir de ese mismo fatídico 1805 se vieron privados del remanente de los cuatro novenos beneficiales, suplemento que hasta entonces, como vimos, les había sido asignado. La reforma tuvo lógicas consecuencias a nivel económico pero no sólo, porque por otra parte afectó el prestigio del cabildo como cuerpo: el nuevo reglamento, al quitarle el superavit, igualó las rentas de las mesas episcopal y capitular, aumentando así relativamente el poder del obispo. En el gráfico siguiente, que ilustra la evolución de las rentas del prelado y del cabildo, puede comprobarse que hasta entonces la mesa capitular había superado ampliamente a la episcopal en la asignación de las rentas, en particular en los años en que la gruesa alcanzó sus niveles más altos. Ver Anexo gráfico 3

En 1805, entonces, se produjo un reacomodamiento del prestigio y del poder entre ambos polos de poder eclesiástico. El cambio era para los capitulares difícilmente digerible, en particular porque reforzaba la posición de un obispo, Lué y Riega, que desde sus primeros días de gobierno se había ido enemistando progresivamente con su cabildo ${ }^{49}$.

Esta situación conflictiva va a inclinarse favorablemente para el cabildo a partir de la revolución, gracias a la adhesión de la mayor parte de los capitulares al nuevo orden de cosas y a la decidida oposición del prelado peninsular. Los gobiernos revolucionarios tendieron a reforzar el poder del cabildo, concebido como representante del clero secular, "columna vertebral" de la vida eclesiástica a la que debían supeditarse las demás expresiones de la vida religiosa, en particular los regulares. Por lo que hace a la cuestión de los diezmos, luego de la muerte del obispo Lué y Riega en 1812 se estableció un tácito acuerdo entre el poder político y los capitulares que permitirá ganar a ambos una parte de la renta correspondiente a la mesa episcopal.

En 1813, en efecto, la Asamblea elaboró un reglamento para la distribución de los diezmos que juzgamos muy significativo, entre otras cosas porque echa luz sobre el carácter de las disputas del período precedente ${ }^{50}$. La primera medi- 
da que establece el nuevo ordenamiento es el retorno a la división por tercias partes, antigua reivindicación del cabildo eclesiástico que, como sabemos, perjudicaba al erario, al hospital, a la fábrica de la catedral y a sus ministros. Puede pensarse que esta redistribución favorecía también al obispo, pero no es así: el reglamento establece por primera vez, para el prelado, un sueldo fijo de 12.000 pesos, al tiempo que dispone que el resto sea distribuido entre el cabildo eclesiástico y el fisco. Más concretamente: el reglamento de 1813, luego de asignar cortas sumas a algunos oficios eclesiásticos -500 pesos al Fiscal, 100 a los capellanes de coro-, destina el resto de la renta episcopal a un novedoso sistema de jubilación para los capitulares porteños y al tesoro del Estado, que de este modo compensa la reducción provocada en sus dos novenos por el regreso a la división tripartita. La muerte de mons. Lué, acaecida en 1812, permitió por otra parte que el Estado se embolsase también los 12.000 pesos que del tercio episcopal correspondían a la esfera personal del prelado. Beneficios, entonces, para las rentas públicas, que entre 1813 y 1817 no recibieron menos del $40 \%$ de la gruesa, y gran victoria del alto clero local, que pudo compensar en parte la fuerte caída que sus entradas habían sufrido desde 1804 y que se había acentuado luego del efímero repunte de 1810.

\section{Consideraciones finales}

En los últimos decenios coloniales, la arremetida contra los ingresos del alto clero porteño, primero en detrimento de la mesa episcopal y luego de la capitular, constituye una manifestación local de un proceso más general: la ofensiva de la Corona para maximizar la absorción de recursos económicos provenientes de las Iglesias de Indias. La más importante entre las demás medidas económico-financieras tendientes a lograr el mismo objetivo fue la promulgación en 1804 de las leyes de desamortización eclesiástica, que tanta incidencia tuvieron sobre todo en Nueva España a principios del siglo XIX $X^{51}$.

En el caso particular de los diezmos de Buenos Aires, en la segunda mitad del siglo XVIII se verificó además un aumento de la gruesa, como resultado de la expansión económica y demográfica de la región: los 15.983 pesos recaudados en 1776 rondaban los 70.000 a fines de la centuria y en pocos años más llegarían a superar los 100.000. A la Corona no se le escapó el fenómeno, por lo que empezaron a multiplicarse los pedidos de informes y las disposiciones reales tendientes a aumentar la recaudación y a regular la distribución de la masa decimal.

51-Véase Brading D. (1994: 248 y ss); también Levaggi A. (1986). 
Las sucesivas reformas que se realizaron en la administración de los diezmos revelan situaciones conflictivas que enfrentan a distintos sectores del clero: los destinatarios de los cuatro novenos beneficiales, el obispo, el cabildo, el clero de las matrices de Montevideo, Corrientes y Santa Fe, se constituyen como actores que en el interior de la Iglesia disputan parte de estas rentas. Es muy probable que la Corona haya aprovechado estas diferencias para aumentar su participación en los diezmos, en un momento de grandes urgencias financieras. No queda dudas, en cambio, de que las diversas manifestaciones de la "ofensiva" regia suscitaron en cada momento la adhesión de aquellos miembros del clero secular que se vieron favorecidos y el rechazo de quienes fueron perjudicados. Por estas razones es que, en términos generales, podemos afirmar que la distribución de los diezmos constituye un elemento más a tener en cuenta a la hora de analizar la compleja y ambigua anatomía del mundo eclesiástico, lacerado por contradicciones que exceden con mucho las disidencias entre autoridades civiles y religiosas.

¿Cómo termina la historia del diezmo en el Río de la Plata? Cuando el litoral rioplatense, que coincidía en términos generales con la diócesis de Buenos Aires, se desarticuló a nivel espacial durante la primera década revolucionaria, el cobro de los diezmos resultó ya impracticable. La secesión de la Banda Oriental privó a Buenos Aires de su parte desde 1811, y Corrientes y Santa Fe suspendieron el pago en 1815, enfrentadas política y militarmente con la capital. En una reunión del 2 de noviembre de 1820, la Junta Superior de Diezmos lamentaba

"la revaja considerable que ha sufrido la Gruesa de Diezmos despues dela separcion de los diferentes partidos que antes eran dependientes de la Capital..."

Además, al convertirse el litoral en escenario de continuas operaciones militares, tanto la producción agropecuaria como el cobro del diezmo sufrieron alteraciones y se verificaron sólo parcial y espasmódicamente. En 1812 el encargado de la recaudación de los diezmos en Corrientes explicaba a la Junta porteña que

"Estas cobranzas de Diezmos, han tomado un aspecto de libre voluntad en los deudores, tal, que jamas sevió. Se estan deviendo Diezmos del año de 9-10-11 y 12. Mis dilig.as han sido eficazes asta insignuarme con este Gov. ${ }^{\circ}$ pero nada, nada puedo adelantar, y si vs.

52-AGN IX 15-1-21. Diezmos 1796-1816. Votos secretos de la Junta General de Diezmos de Buenos Aires, f. 13. 
no se sirve agitar Provi.da de ese Sup.or Gov.o p.a q.e se auxilie con eficacia, se eterniza el cobro, pues ha llegado el caso de Publicarse Bando por Juez Pedaneo ensu Partido ordenando con multa que nadie pague loque deve. Cosa orrorosa." ${ }^{23}$

En 1821, cuando el Estado independiente de Buenos Aires encaró su proceso de reformas modernizadoras e incluyó entre ellas a la de su Iglesia, el diezmo fue abolido definitivamente ${ }^{54}$. La medida tuvo que ver con la voluntad de eliminar un impuesto considerado característico del Antiguo Régimen y con la intención de Rivadavia y sus allegados sacerdotes (José Valentín Gómez, Diego E. Zavaleta, Julián S. de Agüero) de reformular la arquitectura eclesiástica de acuerdo al ideario reformista, que insistía en este punto en el retorno a la pobreza de la Iglesia primitiva; buscó además, qué duda cabe, favorecer el proceso de expansión ganadera que la élite provincial estaba comenzando a encarar por entonces. Pero hay que dar a la decisión su real alcance: como quedó en evidencia durante el transcurso del debate en la Legislatura y como los cuadrantes de los diezmos revelan de manera más precisa, en ese año final las rentas decimales eran una sombra de lo que habían sido no muchos años atrás: de los 109.212 pesos recaudados en 1805, en 1820 se había pasado a sólo 53.608. En tal contexto, para la Iglesia porteña la decisión adoptada por la legislatura resultaba por demás atractiva: el diezmo sería abolido, serían incautadas las propiedades fundiarias de la Iglesia, y los gastos del culto pasarían a ser asumidos por el Estado como parte de su presupuesto ${ }^{55}$. La opción era audaz y poseía también más trascendentes connotaciones, ya que se reforzaría así la simbiosis entre Estado e Iglesia que caracterizaba al Antiguo Régimen. Pero ésta ya es otra historia.

53-AGN IX 13-1-9. "Carta de Manuel de Vedoya a los Jueces Hacedores de Buenos Aires. hay una carátula que dice "Año de 1812. El Subdelegado de Corr.s sobre las diligencias q.e ha practicado p.a e cobro del Diezmo respectivo á los años de 809,810 y 811 ".

54-Ya en 1820 el gobierno de Buenos Aires había concedido exenciones "a los habitantes de la Campaña en indemnisacion de los muchos males y Sacrificios que les ha inferido la Guerra y desordenes pasados". AGN IX 15-1-21. Diezmos 1796-1816: "Votos secretos de la Junta General de Diezmos de Buenos Aires", f. 13 .

55-El debate sobre los diezmos en Diario de sesiones de la Honorable Junta de Representantes de la Provincia de Buenos Aires, Buenos Aires, Imprenta de la Independencia, s/f. 


\section{Resúmen}

\section{Dinero, poder y religión: el problema de la distribución de los diezmos en la diócesis de Buenos Aires (1776-1820)}

Este artículo aborda el tema de las rentas eclesiásticas provenientes de los diezmos en la diócesis de Buenos Aires, su distribución en el interior de la Iglesia y la porción absorbida por el erario real primero y por el revolucionario luego de 1810 . El análisis se extiende a lo largo de un período que abarca desde la creación del Virreinato del Río de la Plata a la abolición de los diezmos en la Provincia de Buenos Aires en 1821. El texto presenta al lector la evolución de la masa decimal y las sucesivas reformas que a lo largo del período estudiado beneficiaron a diferentes sectores de la jerarquía eclesiástica -obispo, cabildo eclesiástico, párrocos de la catedral y de las iglesias matrices, etc.- y a las arcas del Estado, así como los efectos que sobre la recaudación y la distribución de los diezmos generaron la ruptura con la metrópoli y las consecuentes alternativas político-militares.

\section{Palabras clave:}

- Iglesia - Diezmos - Rentas eclesiásticas -Relación Iglesia/Estado -

\section{Abstract \\ "Money, power and religion: the problem of tithe distribution at the BuenosAires diocese (1776-1820)"}

This article focuses on the ecclesiastical revenues produced by the tithes of the diocese of Buenos Aires, its allocation within the Church, and the portion absorbed first by the Royal Treasury and by the independent governments after 1810. It analyzes ecclesiastical revenues throughout a long period of time, from the creation of the viceroyalty of the Río de la Plata in 1776 until the abolition of the tithes in the Province of Buenos Aires in 1821. This article studies long-term variations in revenue produced by the tithes, and how different sectors within the ecclesiastical hierarchy -bishops, the cathedral chapter, parsons of the cathedral and of the major parishes, etc.- and the State treasury were affected by these changes. Finally, it analyzes how the revolution of independence and the political and military events that followed the break-up of the viceroyalty affected the collection and distribution of ecclesiastical revenues.

\section{Key words}

- Church - Tithes - Ecclesiastical revenues - Church/State relationships - 


\section{Referencias bibliográficas}

*AAVV (1970), Le prêtre hier, aujourd'hui et demain, actes du Congrès d'Ottawa, París-Ottawa.

*AAVV (1992), Historia de la Iglesia en Hispanoamérica y Filipinas, Madrid, Biblioteca de Autores Cristianos, Tomo I.

*ALberigo G. (1964), Lo sviluppo della dottrina sui poteri nella Chiesa Universale. Momenti essenziali tra il XVI e il XIX secolo, Roma-Wien, Herder. *AMARAL S. Y GHIO J. M (1990), "Diezmos y producción agraria. Buenos Aires, 1750-1800", Revista de Historia Económica, VIII, 3, Madrid.

*AUZA N. T. (1981), "Los recursos económicos de la Iglesia hasta 1853. Antecedentes del presupuesto de culto", Revista Histórica, $N^{\circ} 58$.

*AVELLÁ CHÁFER F. (1980), "La situación económica del clero secular de Buenos Aires durante los siglos XVII y XVIII", Investigaciones y Ensayos, $N^{\circ}$ 29.

*AVELLÁ CHÁFER F. (1981), "La situación económica del clero secular de Buenos Aires durante los siglos XVII y XVIII", Investigaciones y Ensayos, $\mathrm{N}^{\circ}$ 30.

*BARRAL M.E. (1998), "Limosneros de la Virgen, cuestores y cuestaciones: la recolección de la limosna en la campaña rioplatense, siglo XVIII y principios del XIX", Boletín del Instituto de Historia Argentina y Americana "Dr. Emilio Ravignani", Tercera Serie, $\mathrm{N}^{\circ} 18$.

*BARRAL M.E. (1996), La Iglesia en la economía y la sociedad de una región de la campaña bonaerense. Pilar, Luján y Conchas, 1770-1820, Tesis de licenciatura, Universidad Nacional de Luján.

*BARRIO GOZALO M. (1982) Estudio socio-económico de la Iglesia de Segovia en el siglo XVIII, Segovia.

*BRADING D. (1994), Una Iglesia asediada: el obispado de Michoacán, 17491810, México, Fondo de Cultura Económica.

*BRAMBILLA E. (1984) "Per una storia materiale delle istituzioni ecclesiastiche", Società e Storia, VII.

*BRUNO C. (1969) Historia de la Iglesia en Argentina, Tomo V, Buenos Aires, Don Bosco.

*CASTAÑEDA P. (1978-1979), "El Sínodo de la Iglesia de Charcas, 1773", Missionalia Hispanica, XXXV-XXXVI.

*CHACALTANA C. (1885), Patronato nacional argentino: cuestiones de actualidad sobre las recíprocas relaciones de la Iglesia y el Estado, Buenos Aires. *CHATELLIER L. (1970), "Société et bénefices ecclesiastiques: le cas alsacien (1670-1730), Revue Historique, CCXLIV. 
*DE LA HERA A. (1992), Iglesia y Corona en la América española, Madrid, Mapfre.

*DI STEFANO R. (1998 b) "Abundancia de clérigos, escasez de párrocos: las contradicciones del reclutamiento del clero secular en el Río de la Plata (1770-1840)", Boletín del Instituto de Historia Argentina y Americana "Dr. Emilio Ravignani", Tercera Serie, Nums. 16 y 17, págs. 33-59.

*DI STEFANO R. (1998), Clero secolare e società coloniale. La diocesi di Buenos Aires nel tramonto del mondo coloniale spagnolo, 1780-1810, tesis doctoral defendida en la Università degli Studi di Bologna.

*DI STEFANO R. (1999) "Poder episcopal y poder capitular en lucha: los conflictos entre el obispo Malvar y Pinto y el cabildo eclesiástico de Buenos Aires por la cuestión de la liturgia”, en prensa, en Memoria Americana, $\mathrm{N}^{\circ} 8$.

*DI STEFANO R. (2000), "Entre Dios y el César: el clero secular rioplatense de las reformas borbónicas a la revolución de independencia", en prensa en Latin American Research Review, $\mathrm{N}^{\circ} 2$.

*ELIAS N. (1982), La sociedad cortesana, México, Fondo de Cultura Económica.

*GARAVAGLIA J. C. (1987), “Crecimiento económico y diferenciaciones regionales: el Río de la Plata a fines del siglo XVIII”, en Economía, sociedad y regiones, Buenos Aires, Ediciones de la Flor.

*GARAVAGLIA J. C. (1996), "El teatro del poder: ceremonias, tensiones y conflictos en el Estado colonial", Boletín del Instituto de Historia Argentina y Americana "Dr. Emilio Ravignani”, Tercera serie, Nº 14, págs. 7-30

*GARCÍA BELSUNCE C. (1988), "Diezmos y producción agrícola en Buenos Aires virreinal", en Investigaciones y Ensayos, No 38, julio-diciembre.

*GARCÍA DE LOYDI L. (1969), EI obispo Lué y Riega. Estudio crítico de su actuación, 1803-1812, Buenos Aires.

*GARZÓN PAREJA M. (1974), Diezmos y tributos del clero de Granada, Granada, Archivo de la Real Chancillería.

*GUASCO M. (1997), Storia del clero in Italia dall'Ottocento a oggi, RomaBari, Laterza.

*GUERRA F.-X. (1989), "Hacia una nueva historia política: actores sociales y actores políticos", Anuario IEHS, IV, págs. 243-264.

*GUERRERO SORIANO C. (1989), Iglesia y sociedad en la Diócesis de Buenos Aires, 1700-1800. Aspectos sociales y económicos. Tesis doctoral defendida en la Universidad de Sevilla.

*IBÁÑEZ RODRÍGUEZ S. (1999), El pan de Dios y el pan de los hombres. Diezmos, primicias y rentas en la diocesis de Calahorra (ss. XVI-XVIII), Logroño. 
*LE BRAS G. (1964), Institutions ecclésiastiques de la Chrétienté médievale, Tome I, Tournai.

*LEVAGGI A. (1986), "La desamortización eclesiástica en el virreinato del Río de la Plata", Revista de Historia de América, Nº 102.

*LEVAGGI A. (1992), Las capellanías en Argentina: estudio histórico-jurídico, Buenos Aires.

*MAYO C. (1991) Los betlemitas en Buenos Aires: convento, economía y sociedad (1748-1822), Sevilla, Excelentísima Diputación Provincial de SevillaJunta de Andalucía.

*MAYO C. Y PEIRE J. (1991), "Iglesia y crédito colonial: la política crediticia de los conventos de Buenos Aires (1767-1810)", Revista de Historia de América, $\mathrm{N}^{\circ} 112$.

*MEUVRET J. (1968), "La situation matérielle des membres du clergé séculier dans la France du XVIIe siècle. Possibilités et limites des recherches", Revue d'histoire de l'Église de France, Tome LIV.

*MOLLAT G. (1937), "Bénéfices ecclésiastiques en Occident", in Dictionnaire de droit canonique, Vol. II, París, Letouzey.

*PLONGERON B. (1967), "Une image de l'Église d'après les 'Nouvelles ecclésiastiques' (1728-1790)”, Revue d'Histoire de l'Église de France, Tome LIII, N ${ }^{\circ}$ 151, Juillet-Décembre, págs. 241-268.

*PLONGERON B. (1969), Conscience religieuse en Révolution. Regards sur l'historiographie religeuse de la Révolution française, París.

*PLONGERON B. (1974), La vie quotidienne du clergé française au XVIIIe siècle, París, Hachette.

*PRICOCO S. (1997), "Da Costantino a Gregoio Magno", in Storia del cristianesimo. L'Antichità, a cura di G. Filoramo e D. Menozzi, Roma-Bari, Laterza.

*PROBST J. (1941), "El costo de vida en Buenos Aires según una encuesta del año 1769", en AAVV, Contribuciones para el estudio de la Historia de América. Homenaje al Dr. Emilio Ravignani, Buenos Aires, págs. 431-442.

*RAVIGNANI E. (1937), Asambleas constituyentes argentinas 1813-1898, Tomo I (1813-1833), Buenos Aires.

*RUSSO C. (1984), Chiesa e comunità nella diocesi di Napoli tra Cinque e Settecento, Napoli, Guida.

*TONDA A (1957), Historia del seminario de Santa Fe, Santa Fe, *UDAONDO E. (1949), Antecedentes del presupuesto de culto en la República Argentina, Buenos Aires.

*URQUIZA F. (1993), "Etiquetas y conflictos: el obispo, el virrey y el cabildo en el Río de la Plata en la segunda mitad del siglo XVIII", Anuario de Estudios 
Americanos, Tomo L, № 1, págs. 55-100.

*VILANOVA E. (1989), Historia de la teología cristiana, Vol. II, Barcelona, Herder. 


\section{ANEXO GRAFICOS}

Gráfico 1 "Evolución de los diezmos de Buenos Aires en pesos, 1776-1820"

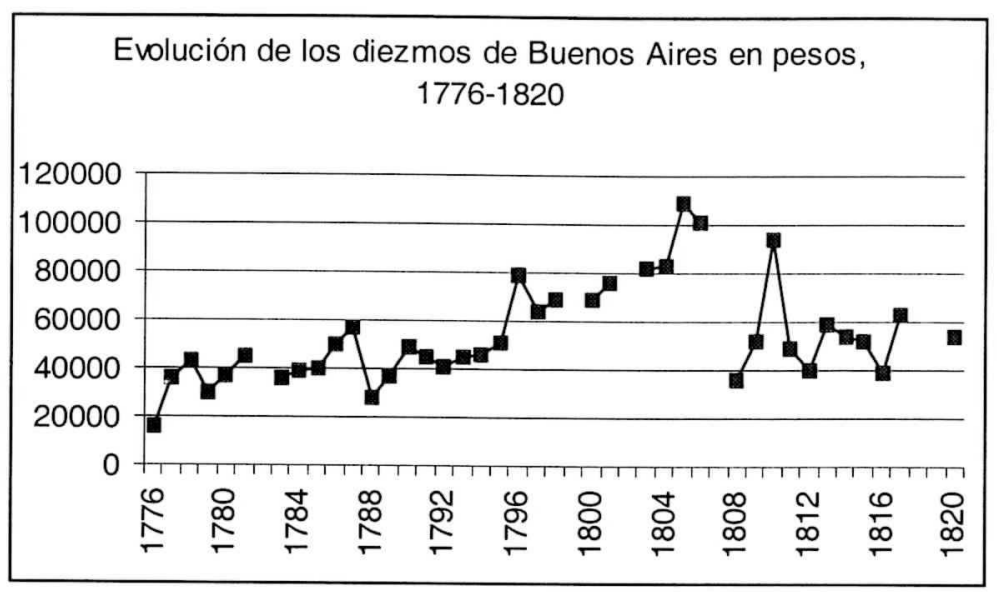

Gráfico 2 "Diezmos percibidos por el estado"

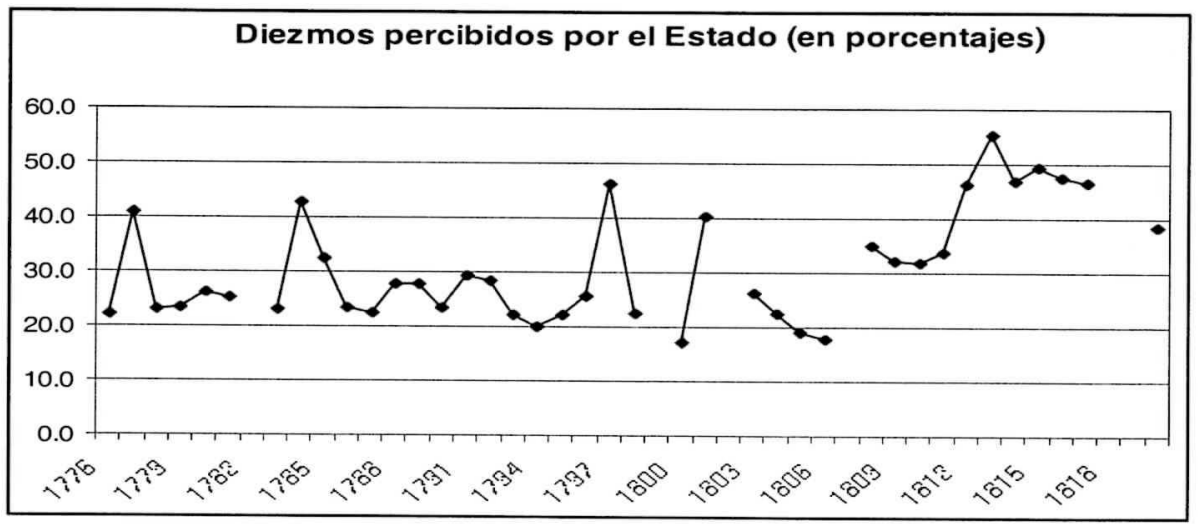


Gráfico 3 "Mesas Episcopal y capitular"

\begin{tabular}{|c|c|c|}
\hline Año & obispo & cabildo \\
\hline 1776 & 3625 & 3625 \\
\hline 1777 & 8536 & 10185 \\
\hline 1778 & 10076 & 13095 \\
\hline 1779 & 7014 & 7311 \\
\hline 1780 & 8783 & 10652 \\
\hline 1781 & 10617 & 14118 \\
\hline 1782 & 10305 & \\
\hline 1783 & 8394 & 9917 \\
\hline 1784 & 8949 & 10965 \\
\hline 1785 & 13260 & 11779 \\
\hline 1786 & 11715 & 16190 \\
\hline 1787 & 13450 & 19467 \\
\hline 1788 & 6415 & 6415 \\
\hline 1789 & 8617 & 11774 \\
\hline 1790 & 11491 & 15767 \\
\hline 1791 & 9850 & 12879 \\
\hline 1792 & 9004 & 11760 \\
\hline 1793 & 9955 & 13077 \\
\hline 1794 & 10408 & 14605 \\
\hline 1795 & 12144 & 17002 \\
\hline 1796 & 18612 & 29219 \\
\hline 1797 & 15019 & 22432 \\
\hline 1798 & 16306 & 24863 \\
\hline 1799 & 16783 & \\
\hline 1800 & 17193 & 24855 \\
\hline 1801 & 17864 & 27807 \\
\hline 1802 & 20777 & \\
\hline 1803 & 19510 & 30837 \\
\hline 1804 & 19761 & 31422 \\
\hline 1805 & 25971 & 25971 \\
\hline 1806 & 21294 & 21294 \\
\hline 1807 & 16989 & \\
\hline 1808 & 7300 & 7300 \\
\hline 1809 & 19792 & 10792 \\
\hline 1810 & 19571 & 19571 \\
\hline 1811 & 9948 & 9948 \\
\hline 1812 & 8009 & 8009 \\
\hline 1813 & 18252 & 18252 \\
\hline 1814 & 16771 & 16771 \\
\hline 1815 & 16073 & 16073 \\
\hline 1816 & 11921 & 11921 \\
\hline 1818 & 19750 & 19750 \\
\hline 1819 & 16074 & \\
\hline 1820 & 16074 & \\
\hline & 16552 & 16552 \\
\hline
\end{tabular}

